\title{
A Scenario Model for Mine Water Management under Extreme Climate Variability
}

\author{
$\underline{\text { Mingwei Zhou }}^{\text {a }}$, Damian Barrett ${ }^{\text {b }}$, Yun Chen ${ }^{\text {b }}$, Lei Gao ${ }^{c}$, Susan Cuddy ${ }^{\text {b }}$, \\ Zahra Paydar ${ }^{\mathrm{b}}$, and Luigi Renzullo ${ }^{b}$ \\ ${ }^{a}$ CSIRO Ecosystem Sciences, 37 Graham Road, Highett, VIC 3190, Australia \\ ${ }^{b}$ CSIRO Land and Water, GPO Box 1666, Canberra, ACT 2601, Australia \\ ${ }^{c}$ CSIRO Land and Water, Private Mail Bag 2, Glen Osmond, SA 5064, Australia \\ Email:mingwei.zhou@,csiro.au
}

\begin{abstract}
Managing mine water under extreme climate variability requires the capability to find trade-offs among multiple competing goals. In order to identify the relationships among these goals, we need to carry out case studies in selected mines based on those events happened in the past and those might occur in the future. However, these types of case studies are often isolated and lack of coherence when an optimal solution is sought at a regional scale with multiple mine sites. One of the key challenges is the lack of the context and scope for identifying and quantifying the causal and inter-dependency relationships among the factors that constrained the competing goals. Therefore it is difficult to capture the actual requirements which are essential to the development of a decision support system for mine water management.

This paper presents a holistic approach to capturing the requirements for mine water management through the design of a scenario model for supporting case studies. The scenario model is depicted through three perspectives: the business perspective shows the mining activities and decisions according to their business hierarchies, such as within a mine or across several mines or companies. The profiles of a number of mines are collected and anonymised to form a hypothetical mining company and put into a geographical location under investigation; the environment perspective represents all the climate change patterns, such as rainfall and catchment histories and weather forecast data; the decision perspective demonstrates how alternative decisions on water management strategies would impact on the operations of the given mine sites in the selected environmental conditions.
\end{abstract}

A number of case studies have been constructed based on the designed scenario model, such as the proactive water management according to weather forecasts, the assessment of the effectiveness of water sharing and trading among multiple mine sites, as well as the evaluation of the costs and benefits of establishing water management infrastructure in mine sites.

Keywords: Mine Water Management, Scenario Modelling, Requirement Engineering, Case Studies 


\section{INTRODUCTION}

Water sources used in mining industry are mainly from rainfall catchments. Consequently, climate change has a great impact on water supply to mine sites. For example, Queensland's Bowen Basin coal mines operate in one of the most highly variable climates in the world. The single most important factor determining the rainfall variability in Queensland is the El Nino Southern Oscillation (ENSO) phenomenon which links ocean circulation and climate variation on a period of approximately 3 years. During the El Nino phase, the chance of drought in Queensland doubles while under La Nina conditions above average rainfall is prevalent. In addition, ENSO is reinforced or dampened by the Inter-decadal Pacific Oscillation (IPO) operating on a much longer time scale of 20-30 years, compounding the variability and unpredictability of long term climate.

These highly variable climate conditions, leading to excess or deficient water on mine sites, underscore the need for the development of improved water management strategies. These strategies must be able to achieve at least the dual goal of ensuring water security for production while at the same time managing water quantity and quality stored in ways that render discharge compliant with regulations.

In order to develop an optimal strategy for managing mine water, we need to have a comprehensive understanding of the "scenario" on how the mine would operate in the future. The Intergovernmental Panel on Climate Change (IPCC) gave a broad definition of a "scenario" as "a coherent internally consistent and plausible description of a possible future state of the world" (IPCC, 1994). In our case, a "scenario" is used to depict the likely state of mine operation in which water management strategies are going to be developed and validated.

The scenario models are not intended to be predictions but a "description" of a future state of the climate conditions and mine operation practices. They will serve as a context where the efficiency and effectiveness of a water management strategy could be assessed and validated. Different scenarios can be developed to depict different climate patterns, as well as alternative water management practices, enabling us to conduct "what-if" analysis on the costs and benefits of different water management strategies.

This paper presents the design of such kind scenario models to be used to capture and communicate a common understanding of the requirements for an optimised water management strategy. The following Section will provide a brief explanation on how the scenario modelling methodology works. Section 3 details the scenario models and Section 4 further elaborates on the design of case studies based on the scenario models.

\section{METHODOLOGIES FOR SCIENARIO MODELLING}

Scenarios have been used in many areas for different purposes. They represent one of the main tools in climate change analyses. They are characterised by the assessment of future developments in complex systems that often are inherently unpredictable, are insufficiently understood, and have high scientific uncertainties (Carter et al., 2001). Managing mine water under extreme variability is a typical situation where scenarios could be used as a potentially effective tool.

Constructing a scenario model for mine water management requires the handling of a large number of interdependent factors and involves collaboration from a group of people with different disciplinary backgrounds. Here we propose a systematic approach which models the scenario from three different perspectives, representing three different groups of stakeholders' interests.

The business perspective represents what miners would be interested, such as the location of the mine site, its product processes, and its water storages. The environment perspective represents all the climate change patterns, such as rainfall and catchment histories and weather forecast data. The decision perspective demonstrates how alternative decisions on water management strategies would impact on the operations of the given mine sites in the selected environmental conditions.

Our proposed approach is to design a set of scenarios to capture the requirements in mine water management. This consists of a hypothetical mining region somewhere in the Bowen Basin, which synthesized from several real but anonymised mine sites. A set of likely extreme weather conditions are also reconstructed to provide "what-if" scenarios to test and validate our mine water management strategies. 


\section{CONSTRUCTION OF A SCENARIO MODEL}

\subsection{The Business Perspective}

The business perspective of the scenario model is intended to depict the state of mine water management system. Figure 1 illustrates a simplified diagram of mine water system in a single mine site.

All mining operation tasks that require the use of water, such as coal handling and processing or dust suppression, are abstracted as "water tasks". Water sources for mines are stored in two reservoirs: the "raw water storage" that collects the rainfall and runoff from the undisturbed catchment areas. It may also receive water through pipeline supply. The "worked water storage" collects reusable worked water and the rainfall \& runoff from the pits and surrounding disturbed areas, and possibly overflows from the raw water storage as well. Discharges to rivers are permitted and when they are compliant with the

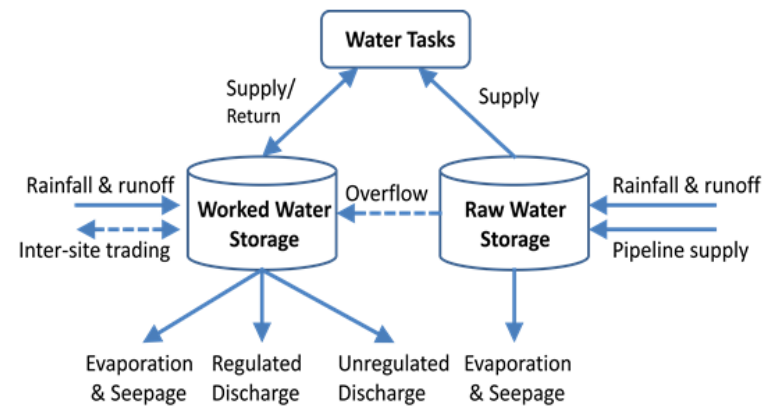

Figure 1. Mine water system regulations on water quantity and quality at the given river flow conditions. Unregulated discharges should be avoided by all means as they pose severe negative social and environmental impacts.

We identified 16 coal mine sites from the Bowen Basin region. These 16 mine sites are mostly actual operational mines studied in previous projects, but their exact identities will be anonymised through altered geographical locations and production details.

Water accounts for each of these mines are available from the WaterMiner (Silvester and Callaghan, 2008), the datasets will be conditioned and calibrated for use in our scenario model.

In addition to assess the water management strategies in a single mine site, we also attempt to explore the feasibility of water transferring among multiple mine sites within the region. Figure 2 illustrates an example of pipeline connections among the 16 mine sites.

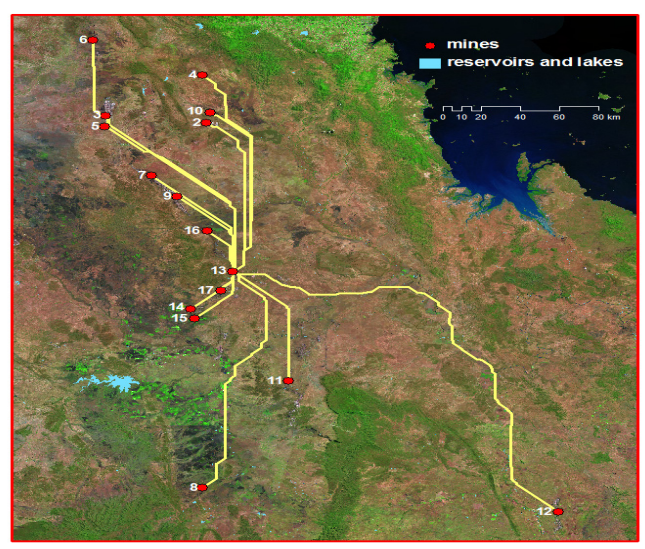

Figure 2, An example of pipeline connection scheme for 16 mine sites

\subsection{The Environment Perspective}

The environment perspective looks at the environmental constraints and opportunities for water capturing and regulated discharging. The water capturing capability is determined by the climate (mainly rainfall) and the surrounding landscape that is permitted to capture runoff. The permitted discharge of treated worked water is constrained by the natural flow rate of designated (nearby) rivers or creeks.

Historical climate database for the 16 mine sites can be established by integrating rainfall and evaporation (ET) data for the study areas. Required data can be downloaded from selected weather stations from SILO (http://www.longpaddock.qld.gov.au/silo/datadrill/index.php) website which provides an enhanced climate data bank hosted by The Science Delivery Division of the Department of Science, Information Technology, Innovation and the Arts (DSITIA), Queensland Government.

The runoff values can be estimated through a simplified rainfall- runoff model. The data required for this calculation includes the size of the catchment areas (including the proportions of the disturbed catchment areas) and the surface areas of the water storages. The volumetric rainfall-runoff factors for disturbed and undisturbed catchment areas can be used to calibrate the model for individual mine site against the observed catchment. 
Figure 3 shows the estimated annual water catchment in the 16 mine sites over the period 01/07/1977 to $30 / 06 / 2007$. The figure also highlights the historical climate variability in very wet (in red) and very dry (in blue) years.
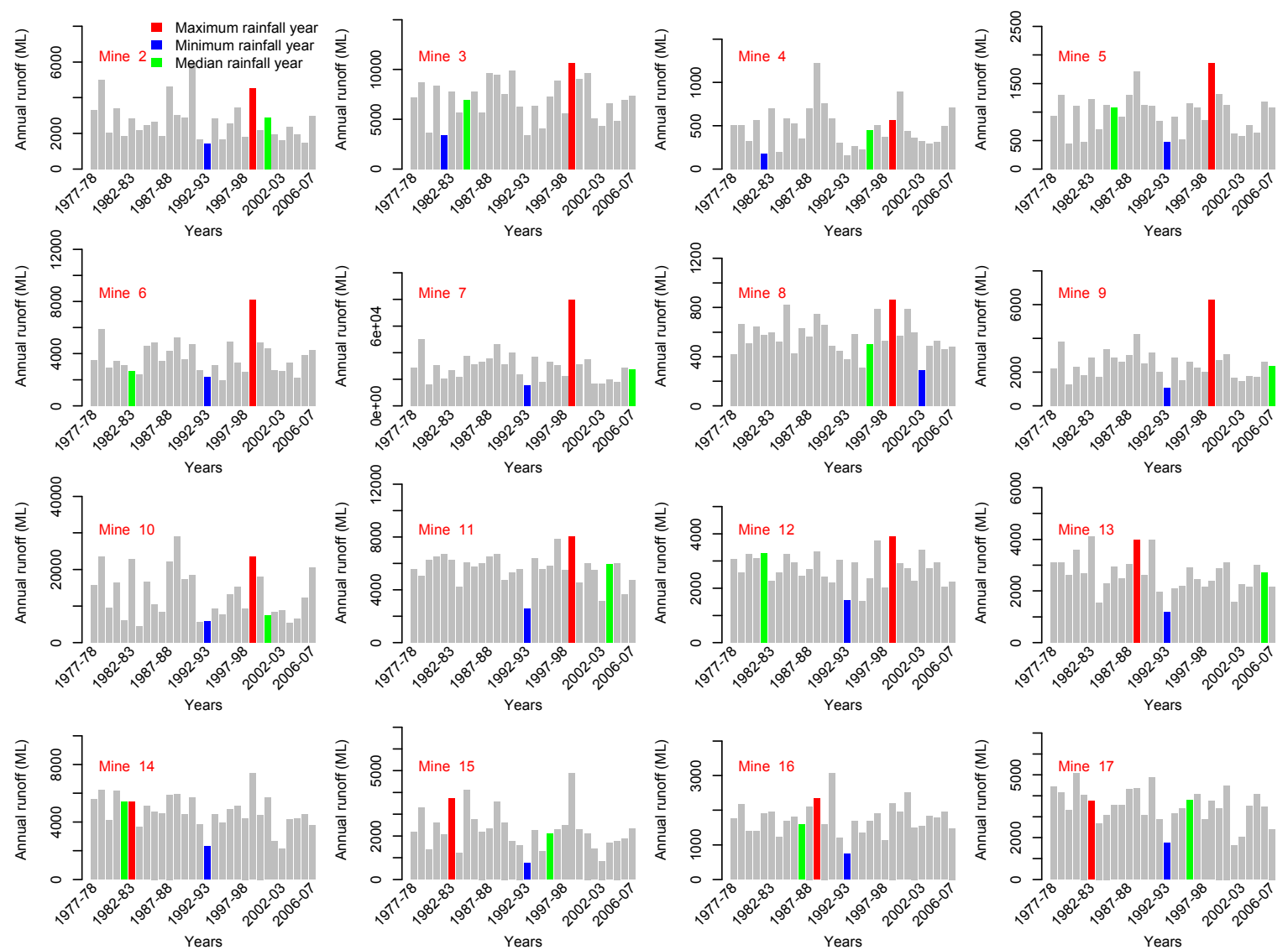

Figure 3. Annual runoff in the 16 mine sites (over the period 01/07/1977 - 30/06/2007)

Based on these historical catchment data, we can also derive a number of climate patterns to simulate the extreme climate variability. These extreme climate patterns include: lasting dry years, lasting wet years, long dry years followed by wet years, long wet years followed by dry years, and extreme wet and dry seasons. These extreme climate patterns could be used to test and demonstrate the effectiveness of any proposed optimal strategies.

\subsection{The Decision Perspective}

With the Business Perspective capturing the mine operation practices, and the Environment Perspective capturing the climate impact on water capturing and discharging, the Decision Perspective is looking at how to develop strategies to best meet the business needs with the environmental constraints and opportunities.

As we discussed earlier, the key challenge for water management under extreme climate variability is to maintain the mine water storage in an optimal level, so that it will ensure water security for mine operation and eliminate the needs for unregulated discharges.

Figure 4 illustrates the issues related to the optimisation of water storage levels. At the current time $t 0$, the water storage level is assumed to be at an optimal level. The decision would be the setting of the optimal target of storage level for a future time $t 1$. 
There might be no extreme weather conditions in the foreseeable future, the mine could run "business as usual", and the water level at time $t 1$ would be $T A$. If a dry season is expected, the mine operator may decide to accumulate more water by treating and reusing more worked water, and may withdraw more water through pipelines as permitted by pump capacities and quotations. With this approach, the target water storage may lead to a higher level at $T B$. However, if a heavy rainy season is expected, the mine may decide to stop drawing water from the pipelines, and may seek opportunities to discharge the treated worked water whenever the regulation permits. In this situation we may expect the targeted water storage drop to a lower level at $T C$.

To maintain water storage level in an optimal state, we need to keep it within an optimal or safe zone constrained by an upper boundary limit and a lower boundary limit. The upper boundary indicates that if the water storage level is kept under this limit, the mine site would have no need to incur any unregulated discharges of excess water in any climate conditions in the foreseeable future, with a pre-decided confidence of, say, once in 50 years. Similarly, the lower boundary indicates that if the water storage level is kept above that limit, the mine site would have sufficient water to meet its mine operation needs in any climate conditions in the foreseeable future, with a similar pre-decided confidence of, say, once in 50 years.

Setting these boundaries would need to fully consider both the business perspective (such as the water storage capacities, pump capacities, water allocations through pipelines etc.) and the environmental perspective (such as historical rainfall and evaporation data, catchment infrastructure etc.). Furthermore, we will also need to investigate the concepts of resilience of the mine water management system (Wang and Blackmore, 2009), therefore be able to establish a method to quantify these boundary values.

\section{CASE STUDIES WITH SCENARIO MODELS}

Three case studies have been developed to make use of the scenario model to explore the optimal mine water management strategies. These case studies are expected to be conducted one by one at three stages. Some initial studies by the authors (Gao et al. 2013a; Gao et al. 2013b; Gao et al. 2013c) have provided a solid foundation for carrying out the case studies proposed here.

The first case study will look at the feasibility of a dynamic water management strategy in a single mine site where the mine operator can take proactive measures to accumulate or discharge water according to the weather forecasts. The second and third case studies further the investigation by exploring the opportunities of sharing and trading water among multiple mine sites.

\subsection{Case Study 1 - Single Mine Site Water Usage Optimisation}

The first step of this case study aims to establish a baseline case of mine water management, in which we can assess the individual mine's water account (without any optimisation) for five different climate patterns. This will help us estimate the unregulated discharges and unmet water demand in a daily bases.

Following on that, we assess the potential impact of various optimisation strategies for individual mine site, and estimate the new unregulated discharges and unmet water demands in a daily bases and compare the results with the baseline cases established in the first step.

With the optimisation results from the above two stages, we will be able to further explore the forecast based decision support system for daily operational water management actions. The outcomes would enable us to assess whether there exist any all-round best strategy that works for all five climate conditions. If such an allround best does not exist, we would still be able to identify some strategies that are the best for a certain number of climate patterns. We would also be able to analyse why some strategies did not perform as good as in some other climate patterns, and pick an appropriate strategy for the upcoming (forecasted) climate condition.

As forecasts are always with uncertainties, and a short term forecast is likely more accurate than the longer term forecasts, we would need to have necessary algorithm to adjust our strategies when more accurate forecasts are available. Similarly, we would also need necessary algorithm to adjust our strategies to compensate the differences between the forecasted rainfall and actually observed rainfalls.

Finally we need to formulate a general guideline on the methodologies and strategies for achieving the most cost effective mine water management actions. 


\subsection{Case Study 2 - Multiple Mine Site Water Sharing}

In an earlier study by Barrett et al. (Barrett et al., 2010), it was identified that if the excess worked water from one mine site could be transferred to other mine sites, it will not only eliminate unregulated discharges but also save substantial amount of water (340 ML of water could be transferred among the 16 mine sites per year). The study used the water storage level as the indicator to measure the willingness of a mine to pump out its water.

In this case study, we aim to further explore other factors that influence the decisions, such as the forecasted rainfalls in a proactive water management strategy. To simplify the case study, we assume that all mines belong to the same company and the worked water storages in all sites are connected, the worked water can be transferred from one storage to another, with consideration of the operational transport costs only.

We could assume that the needs for water transferring are assessed weekly according to their propensity. No water transfer would be necessary if no mine is too wet or too dry in normal operations, except as a proactive/preventive measure. Water quality and salt concentration in worked water should also be considered in water transfer, but should not affect the decisions on water transfer (unconstrained variable).

If a mine is deemed to have excess water and may incur unregulated discharge, its worked water will be transferred to the driest or nearest dry mines. Similarly, if a mine is too dry and deemed to have insufficient water, its worked water storage will be replenished by the wettest or nearest wet mines. The unit of transfer (the volume of water to be transferred) could be one pump's daily capacity. Multiple units could be transferred if necessary through iterations until no further transfer is necessary.

After the completion of the weekly water transfer, we can increase or decrease the frequency to daily or monthly. According to the findings from these assessments, we may further explore high frequencies or lower frequencies to see whether they make any significant differences.

Based on the assessment, we can further identify the mines that do not benefit from the water sharing and could be disconnected from the water transferring network. We could assess the performance of a limited network under different transferring strategies and climate patterns.

With this case study, we could also assess the overall resilience or capability to respond to the extreme climate variability by comparing the outcomes with those from the case study 1 conducted in the first stage. We may also be able to assess the optimal number of connections among the mine sites, as well as the capacity of pumps and transfer frequencies based on different criteria (eg, minimal costs, or maximal reliability). This would be useful in assessing the merit of the one-off infrastructure costs for pipelines and pumps. We might need to look at both the all-connected case and limited connection cases.

In summary this case study would present us with a big picture on the cost effectiveness of water sharing among multiple mine sites from the operational perspective. This will also enable us to further analyse the necessary policies and incentives for encouraging water sharing among mine sites.

\subsection{Case Study 3 - Multiple Mine Site Water Trading}

In this case study we will conduct the same assessments as in case study 2, but will further incorporate the consideration of the value of water, and the value at risk. We will assume each mine sites as an independent business unit. While all mine sites are cooperative, and would collaborate in mitigating overall water management risks, provided that the strategies and actions are fair and properly compensated. We need to analyse the situations from individual mine's consideration - to assess whether it wants to trade water, when, how much, and at what price.

This would be a major exercise of assessment, and we will need additional tools for the simulation and analysis, such as the multi-criteria decision making techniques (Chen et al, 2013). In addition to the quantification of the costs and benefits of each strategies and actions, we will need to understand the mine operators' business behaviour in making their decisions. An agent-based modelling and simulation tool would be effective for this type of case studies.

Each agent will be used to simulate an individual mine site's water manager. The agent will be given a set of indicators and rules for its mine water storages and demands, the forecasts of rainfall, and the costs and availability of water in the market. Each agent then needs to decide whether it wants to buy or sell water on the market. It needs to assess its own position, and needs to identify the best bet - either making an offer or accepting a deal. 
Various factors that influence the decisions could be considered here individually or jointly, such as the forecasted rainfall in the following weeks and months, the costs and capacity for delivering (pumping) the water, or management styles (eg, proactive, conservative, emergency management). The trading prices could be positive, zero, or even negative if necessary.

Quantitative assessment of likelihood and consequence of value at risk is also essential. This would include potential indirect impacts in social, economical and environmental perspectives. This will also provide the bases for assessing the effectiveness of risk mitigation strategies in the extreme events of drought or flooding.

\section{DISCUSSION}

This paper presented a methodology for construction a scenario model for exploring the optimal strategies for managing mine water under extreme climate variability. It aims to provide a research context for developing a rigorous and objective technique for exploring management strategies, assessing risk and addressing the challenges of both excess and insufficient water on mine sites.

The scenario model also provided necessary foundation for exploring different case studies and developing a climate-driven hierarchical model of a mine water system, embedded within an optimization scheme capable of examining the feasibility of optimal pathways for managing water on sites.

\section{ACKNOWLEDGMENTS}

This project is funded by the Australian Coal Association Research Program (ACARP) and CSIRO Water for a Healthy Country National Research Flagship.

\section{REFERENCES}

Barrett, D., Moran, C., Cote, C., 2010. A Method for Estimating the Potential Trading of Worked Water among Multiple Mines. Mine Water and the Environment 29(2) 92-98.

Chen, Y., Yu, J. and Khan, S., 2013. The spatial framework for weight sensitivity analysis in AHP-based multi-criteria decision making. Environmental Modelling \& Software 48:129-140.

Carter, T.R. et al. 2001. Developing and applying scenarios, in McCarthy, J.J. et al. (Eds.), Climate Change 2001: Impacts, Adaptation and Vulnerability. Cambradge University Press, Cambridge, pp. 145-190.

Côte, C.M., Moran, C.J., Hedemann, C.J., Koch, C., 2010. Systems modelling for effective mine water management. Environmental Modelling \& Software 25(12) 1664-1671.

DRET, 2008. Water management, Leading practice sustainable development program for the mining industry. Department of Resources, Energy, and Tourism: Australia.

Gao, L., Barrett, D. , Chen, Y., Zhang, X.-F., Cuddy, S., Zhou, M., Paydar, Z., and Renzullo, L., $2013 a$. Secure mine water use with compliant discharge, submitted to International Congress on Modelling and Simulation, Adelaide, South Australia, December 1-6, 2013.

Gao, L. Barrett, D., Chen, Y., Zhou, M., Cuddy, S., Paydar, Z., and Renzullo, L., 2013b. A process-based simulation model for strategic mine water management, submitted to International Congress on Modelling and Simulation, Adelaide, South Australia, December 1-6, 2013.

Gao, L., Connor, J. D., Barrett, D., Chen, Y., and Zhang, X.-F., 2013c. Strategic water management for reliable mine water supply under dynamical climates, submitted to International Congress on Modelling and Simulation, Adelaide, South Australia, December 1-6, 2013.

IPCC, 1994. IPCC Technical guidelines for assessing climate change impacts and adaptations. In Carter T.R., Parry M. L., Harasawa H., Nishioka S. (eds.). Part of the IPCC Special Report, IPCC Working Group II.

Moran, C.J., Cote, C., McIntosh, J., Hedemann, C., Silverster, N., 2006. Northern Bowen Basin water and salt management practices. ACARP report C15001

Silvester N., Callaghan D., 2008, WaterMiner V2.0 User Manual, Sustainable Minerals Institute, University of Queensland. Available at http://waterminer.smi.uq.edu.au/doc/WM_User_Manual_v2.0.pdf

Wang, C.H. and Blackmore J.M., 2009. Resilience Concepts for Water Resource Systems, Journal of Water Resources Planning and Management, Vol. 135, No. 6, November 1, 2009 